\title{
EX-POST ASSESSMENT OF HETEROGENOUS EFFECTS OF TRADE AGREEMENTS: THE CASE OF TURKEY
}

\author{
DOI: 10.17261/Pressacademia.2021.1380 \\ JBEF- V.10-ISS.1-2021(2)-p.12-23
}

\section{Ozlem Demiroglu1, Elcin Aykac Alp²}

${ }^{1}$ Legislation and Education Consultant, $\mathrm{PhD}$, Istanbul, Turkey ozlemdemiroglu@gmail.com , ORCID: 0000-0002-4000-9486

${ }^{2}$ Istanbul Commerce University, Department of Economics, Istanbul, Turkey ealp@ticaret.edu.tr, ORCID: 0000-0001-9076-2102

To cite this document

Demiroglu, O., Aykac Alp, E. (2021). Ex-post assessment of heterogenous effects of trade agreements: the case of Turkey. Journal of Business, Economics and Finance (JBEF), V.10(1), p.12-23.

Permanent link to this document: http://doi.org/10.17261/Pressacademia.2021.1380

Copyright: Published by PressAcademia and limited licensed re-use rights only.

\section{ABSTRACT}

Purpose -Free trade agreements (FTA) are prominent features of international trade. The proliferation of FTAs over the past 20 years is one of the most prominent aspects of the global economy. Turkey has also signed many FTAs in this period on the basis of obligations stemming from customs union with European Union. FTAs aim to increase trade flows and welfare through liberalizing trade and achieving a deeper integration between partners. In this respect, FTAs are getting more and more important as international trade is a crucial tool to boost the economic development. Indeed, getting the utmost benefit from FTAs is very important for Turkey and other developing countries. Regarding the increasing importance of FTAs, the ex-post effects of FTAs on Turkey's trade are examined in this paper.

Methodology - In the light of recent techniques, structural gravity model is used in this study. Trade data used consists of aggregate trade flows among pairs of 90 countries from 1988-2016, 29 years in total. As the estimation technique, Ppml_panel_sg command is used. This is an estimation command for Poisson pseudo-maximum-likelihood (PPML) regression for panel gravity models with time varying importer and exporter fixed effects and time invariant pair fixed effects.

Findings-The results indicate the econometric evidence of the impact of FTAs on Turkey's trade. When all FTAs are considered at macro level, the results suggest that, FTAs had a statistically significant positive effect on exports and imports of Turkey. However, at micro level, there is substantial variation and heterogeneity in the agreement specific effects and trade direction specific effects within the agreement.

Conclusion-This paper provides the first evidence that the impact of FTAs are heterogenous and not all the FTAs affected the trade of Turkey in the same positive way. Even within the same agreement, the effects vary considerably depending on the direction of trade.

Keywords: International Trade, Free Trade Agreements, Gravity Model, Heterogeneity JEL Codes: F10, F13, F15

\section{INTRODUCTION}

The proliferation of economic integration agreements (EIA), notably free trade agreements over the past 20 years is one of the most prominent aspects of the global economy (Bergstrand, Larch and Yotov 2015). Given the multitude of FTAs in existence, there is a vast literature on the impacts of FTAs on trade. Broadly speaking, all FTAs aim to increase the trade and welfare. It is expected that FTAs increase the trade because the liberalization of the trade makes imports cheaper and these imported products replace domestic production or imports from the rest of the world. This basic theory dates back to Viner (1950) and Meade (1955). But "Do FTAs really increase the trade and if increase, to what extent?" This question is asked more and more and in search of an answer, measuring and assessing the impacts of FTAs became a popular topic among both academics and policymakers. Getting the utmost benefit from the FTAs is very important for developing countries as the increasing importance of international trade in economic development is considered. In this respect, this study is examining Turkey's FTAs in order to fully understand the expost effects of FTAs on her trade. 
Turkey's policy on FTAs is determined on the basis of obligations stemming from customs union (CU) with European Union (EU). According to Article 16 of the Decision 1/95, establishing the customs union, Turkey has committed to harmonize her commercial policy with that of EU's. In this context, Turkey has been required to align itself progressively with the preferential customs regime of the Community and adopt all Free/Preferential Trade Agreements and Generalized System of Preferences (GSP) of EU. Based on this requirement, Turkey has signed FTAs with many countries. First FTA of Turkey is signed in 1991 and entered into force in 1992 with EFTA States (Iceland, Liechtenstein, Norway and Switzerland). This is the only FTA Turkey has signed before the CU. Following the EFTA agreement, FTAs with Israel (1997), Romania (1998), Lithuania (1998), Hungary (1998), Estonia (1998), Czech Republic (1998), Slovak Republic (1998), Bulgaria (1999), Poland (1999), Slovenia (2000), Latvia (2000), Macedonia (2000), Croatia (2003), Bosnia and Herzegovina (2003), Palestine (2005), Tunisia (2005), Morocco (2006), Syria (2007), Egypt (2007), Albania (2008), Georgia (2008), Montenegro (2010), Serbia (2010), Chile (2011), Jordan (2011), South Korea (2013), Mauritius (2013), Malaysia (2015), Moldova (2016), Singapore (2017), Faroe Islands (2017), Kosovo (2019), Venezuela (2020) and United Kingdom (2021) were signed and entered into force gradually at the dates mentioned. Among these agreements, the ones signed with Romania, Lithuania, Hungary, Estonia, Czech Republic, Slovak Republic, Bulgaria, Poland, Slovenia, Latvia, Croatia are terminated when these countries joined the EU. Agreement signed with Syria is suspended in 2011 and agreement signed with Jordan is suspended in 2018.Turkey has also signed FTAs with Lebanon, Sudan and Qatar but these FTAs are not in force yet. So currently Turkey has 22 FTA's in force.

Many of the countries that Turkey has signed FTAs are relatively small trade partners of Turkey. In the last three years, among Turkey's top 20 export markets, only Switzerland, Israel and Egypt had an FTA with Turkey. Similarly, among the top 20 sources of imports of Turkey only Switzerland and South Korea had an FTA with Turkey. As a consequence, though Turkey concluded various FTAs, still relatively small amount of trade takes place pursuant to FTAs. The percentage of exports to FTA countries in total exports is 8,75 and the percentage of the imports from FTA countries in total imports is 6,68 on average between 1996-2017 according to authors' own calculations based on data from Turkish Statistical Institute. Here there are two important questions: "What Turkey expects from FTAs?" and "Did she get what she expected?" Turkey's main expectations from FTAs are to increase her trade through better market access opportunity and to provide better competition for Turkish exporters especially when the EU exporters are considered. To answer the second question, which is the aim of this study, the effect of FTAs on Turkey's trade is estimated by using structural gravity model. The results of the estimations suggest that FTAs increased the trade at the macro level. However, effects of individual agreements differ widely across the agreements and within the agreement depending on the direction of trade. Therefore, gains from FTAs can't be taken for granted all the time. This finding is quite in line with the research of Carrere (2006), Kohl (2014) and Baier, Yotov and Zylkin (2016) on the heterogeneous effects of individual FTAs. The remainder of this paper is organized as follows: Section 2 covers the literature review, section 3 describes the econometric methodology and the data, section 4 presents the results and section 5 is the conclusion.

\section{LITERATURE REVIEW}

In this section, the literature will be reviewed with a focus on two subjects. First, the gravity model and advances in the application over time, second, application of the gravity model for estimating the effects of FTAs.

The gravity model is an econometric model that relates bilateral trade flows between country pairs to an economically influential variable of countries/country pairs. It is first introduced by Tinbergen in 1962. The gravity model of Tinbergen which is derived from Newton's law of "universal gravitation" proposes that bilateral trade flows between two countries are positively related to the national incomes of the partners and negatively related to the bilateral distance between them in the simplest form (Tinbergen 1962). The model's success in correctly estimating bilateral trade flows made it one of the most stable empirical relationships in economics (Benedictis and Taglioni 2011). Since introduced by Tinbergen, the model has been used extensively in international trade literature and it is often referred to as the workhorse of international trade. Though being used extensively, initial applications of gravity model were a-theoretical (Yotov, Piermartini, Monteiro and Larch 2016). Therefore, until recently the gravity model was "an intellectual orphan, unconnected to the rich family of economic theory" due to the absence of an accepted connection to economic theory (Anderson 2011). In time, new research and advances on theoretical foundations of the gravity model showed that, gravity equation can be derived from many different trade theories (De Benedictis and Taglioni 2011).

Among important studies about theoretical foundations of the model, first and one of the most important contributions is by James Anderson (1979). Anderson proposed an explanation of the gravity equation based on a demand function where the goods are differentiated on the basis of the country of origin. Later work includes contribution by Krugman (1980), Bergstrand (1985 and 1989) and Helpman and Krugman (1985) about the theoretical explanation based on monopolistic competition frameworks, contribution by Deardorff (1998) about derivation of the gravity model from Heckscher-Ohlin, contribution by Eaton and Kortum 
(2002) about deriving gravity model on the supply side as a Ricardian structure and contribution by Bernard, Eaton, Jensen and Kortum (2003) and Melitz (2003) about the firm heterogeneity. Another contribution is the work of Anderson and Wincoop (2003) that is considered as a milestone about the theoretical foundation of the gravity model. Anderson and Wincoop popularized the work of Anderson (1979) and contributed to the gravity literature by emphasizing the effects of trade costs and introducing the multilateral resistance term in the gravity equation. The gravity model of Anderson and Wincoop is called theoretical gravity model.

Gravity model is commonly used to investigate the effects of different trade policies especially effect of FTAs on trade flows. The effects of FTAs on trade flows have been on the research agenda since the seminal work of Tinbergen where he studied the effects of BENELUX and Commonwealth membership. In the last 55 years, a lot of research is made on measuring the ex-post effects of FTAs. Kepaptsoglou, Karlaftis and Tsamboulas (2010) and Kohl (2014) provide a review of previous empirical studies about FTAs. However, till recent times, the gravity estimates were highly variable and economically implausible most of the time. Only recently economists have been able to provide unbiased and more precise ex-post effects of agreements on international trade flows (Bergstrand, Larch and Yotov 2015). Examples from recent studies concerning the ex-post effects of FTAs are as follows: Carrere (2006), assessed the effects of EU, ANDEAN, NAFTA, CACM, MERCOSUR, ASEAN and LAIA with gravity model using panel data. The findings of the study showed that, most of these agreements increased intra-regional trade but sometimes reduced the exports to the rest of the world. Baier and Bergstrand (2007), used panel data and estimated the gravity model both with fixed effects and with first differencing method. Their study showed that trade agreements increase trade considerably and have statistically significant lagged effects. Baier, Bergstrand, Egger and McLaughlin (2008), estimated the effects of various economic integration agreements including the EU. They applied gravity models with and without multilateral resistance terms and used estimation techniques such as first differencing and fixed effects. Their conclusion suggests that the effect of EU membership is economically significant even larger than the amount estimated in the previous studies. Mölders and Volz (2011), studied the impact of FTAs on the trade flows of East Asian economies. Their findings suggest that particularly bilateral trade agreements result in significant positive trade effects while the effect of multilateral trade agreements is insignificant in most of the cases. Magee (2008), estimated the effects of regional trade agreements on trade flows by controlling importer-year, exporter-year and country pair fixed effects. The results of the study reveal that there is an anticipatory effect of the agreements which increase the trade and this increase continues over the first 11 years after entry into force. Egger and Larch (2011), studied the trade, GDP and welfare effects of EU's trade agreements with 10 Central and Eastern European Country (CEEC). The results suggest that the agreements increased the trade between EU and CEEC but at the same time they induced trade diversion. Eicher and Henn (2011), investigated the effects of WTO membership and preferential trade agreements such as EU, APEC, CACM, CARICOM, MERCOSUR and LAIA and GSP regime. They concluded that, WTO membership does not have statistically significant effects on trade while trade agreements have a statistically significant trade creating effect which is uneven across different agreements. Baier, Bergstrand and Feng (2014), studied the impact of economic integration agreements on intensive versus extensive margins of trade. Their results suggest that; economic integration agreements affect both the intensive and extensive margins of trade and deeper integration agreements have larger impacts than shallower agreements. Kohl (2014), performed individual estimates for the trade effects and phase-in effects of 166 different economic integration agreement. The results suggest that only about one quarter of the agreements investigated promoted trade and more than half of the agreements had no impact on trade flows. Dai, Yotov and Zylkin (2014), estimated the trade creation and trade diversion effects of FTAs. Their results show that FTAs have trade diverting effects and this effect is stronger for imports than it is for exports. Baier, Bergstrand and Clance (2015), studied the heterogeneity in the effects of economic integration agreements and they concluded that there is heterogeneity in the effects of different trade agreements. Kohl, Brakman and Garretsen (2016), studied the effects of heterogeneous design of trade agreements. Their results indicate that trade promoting effects of agreements change depending on the legal enforceability of the provisions of the agreements. Zylkin (2016), examined the heterogeneity in the effects of trade agreements using NAFTA as an example. The results show that the effects of the agreement are not always symmetrical between the partners. Baier, Yotov and Zylkin (2016), used a two-stage methodology to search for the determinants of the effects of past free trade agreements and obtain ex-ante predictions for the effects of future agreements such as TPP and TTIP. They concluded that the effects of individual agreements differ considerably both qualitatively and quantitatively.

Another part of the literature is the literature for the case of Turkey. Unfortunately, there are just a few studies about the effects of Turkey's FTAs on her trade. Arısoy, Bayar and Çalışkan (2003), used a dummy variable to measure the effects of FTAs on Turkey's trade by using gravity model. Their results suggest that the FTA dummy is not statistically significant suggesting that FTAs had no impact on Turkey's foreign trade. Özkaya (2011), studied the effects of bilateral and multilateral agreements on Turkey's trade using gravity model. In that study as well, the dummy for FTA is found to be statistically insignificant. Türkcan and Pişkin (2016), studied the effects of Turkey's FTAs on the extensive and intensive margins. Their results suggest that FTAs increased intensive 
trade while decreasing extensive trade and the effect on intensive trade is more than the effect on extensive trade. Kütük and Akbostancı (2016), studied the effects of customs union and free trade agreements on Turkey's trade with gravity model. Their results suggest that free trade agreements do not have a statistically significant effect on Turkey's export and import. Frede and Yetkiner (2017) analysed the Turkish export and import flows. The results of their model suggest that the coefficient of FTA is insignificant when aggregate data is used. When measured for selected time periods, some mixed results are obtained depending on the time interval. When sectorally disaggregated data is used, FTA coefficients found to be negative for all sectors with the exception of the export of textiles and footwear.

In addition to these studies, the effects of some of the Turkey's FTAs are included in a few studies in the international literature that estimate agreement specific effects for individual agreements. As an example, Baier Yotov and Zylkin (2016), studied the impact of individual agreements around the world including some agreements of Turkey. Their results suggest that some of the FTAs of Turkey had positive effect on her trade flows while some others had no impact. In this study, aggregated manufacturing trade flows are taken into consideration. The FTA's included in the study are the ones with Bulgaria, Romania, Israel, Poland, Hungary, Tunisia, Egypt and EFTA. According to the results except Egypt and EFTA, the others had a positive impact on trade. Another example is the study of Kohl (2014) where the effects of 166 FTAs including some FTAs from Turkey are estimated. The results suggest that, the effects of Turkey's FTAs on her trade are mixed. Some FTAs had positive effect, some had no statistically significant effect and some had negative effect on her trade. The FTAs included in the study are the ones with Bulgaria, Czech Republic, Estonia, EFTA, Hungary, Israel, Latvia, Lithuania, Macedonia, Poland, Romania, Slovak Republic and Slovenia. According to results, FTAs with Bulgaria, Romania and Slovenia had a positive effect on trade while EFTA had a negative effect and the rest of the agreements had no statistically significant effect on trade.

\section{DATA AND METHODOLOGY}

\subsection{Econometric Methodology and Model}

In this study, it is aimed to examine the ex-post effects of Turkey's FTAs on imports and exports of Turkey. Estimating the ex-post effect of a trade agreement is not easy as the increase in bilateral trade between the partners does not necessarily show the success of FTA. There could be many factors other than the FTA which could affect the bilateral trade volume. Therefore, statistical methods and analysis are required to isolate the effect of FTA among the other factors (Bergstrand, Baier, Sunesen and Thelle 2011). For this purpose, the structural gravity model is used in this study. Trade data used consists of aggregate trade flows among pairs of 90 countries from 1988-2016, 29 years in total. The basic gravity equation has the following multiplicative formulation in general:

$$
X_{i j}=G S_{i} M_{j} \Phi_{i j}
$$

Here Xij represents the value of exports from country $i$ to $j, M_{j}$ represents importer-specific factors which determine the total demand of importer, $S_{i}$ represents exporter-specific factors which determine the total supply of the exporter, $G$ is a variable independent from $\mathrm{i}$ or $\mathrm{j}$ such as the level of world liberalization and $\Phi_{\mathrm{ij}}$ represents the ease of access to the market of importer $\mathrm{j}$ by the exporter i (Bacchetta, Beverelli, Cadot, Fugazza, Grether, Helble, Nicita and Piermartini 2012). In the context of research concerning the theoretical foundation of the gravity equation Anderson and van Wincoop showed that; controlling for relative trade costs rather than the absolute trade costs between exporter and importer is crucial for a well-specified gravity model. In other words, exports from country $i$ to $j$ and imports of country $j$ from country $i$ depend on trade costs not only between $i$ and $j$ but also across all possible export markets and all suppliers. Anderson and van Wincoop (2003) called this relative trade costs "multilateral trade-resistance" (MTR). Omitting these MTR in the gravity model estimation is called "gold medal error" by Baldwin and Taglioni (2006). After the inclusion of MTR, a theoretically founded structural gravity equation takes the following form:

$$
X_{\mathrm{ij}=} \frac{Y_{i} Y_{j}}{Y}\left(\frac{t_{i j}}{\prod_{i} P_{j}}\right)^{1-\sigma}
$$

Here $X_{i j}$ represents the trade flows from country $i$ to country $j, Y$ represents the world GDP, $Y_{i}$ and $Y_{j}$ represent the GDP of countries $i$ and $j$ respectively, $t_{i j}$ represents the cost of importing a good from $i, \sigma$ represents the elasticity of substitution and $\prod_{i}$ and $P_{j}$ represent exporter's outward and importer's inward multilateral resistance terms respectively. If this equation is re-written in exponential form by adding time subscript and an error term, the equation turns into following:

$$
X_{i j, t}=\exp \left(\ln Y_{t}+\ln Y_{i, t} \prod_{i, t}{ }^{\sigma-1}+\ln Y_{j, t} P_{j, t}{ }^{\sigma-1}+\ln t_{i j, t}{ }^{1-\sigma}\right)+\varepsilon_{i j, t}
$$


A number of proxy variables are used to measure the trade costs as they are not directly observable. Trade costs are generally assumed to take the following form in the gravity literature:

$$
t_{i j}=d_{i j}^{\delta_{1}} \cdot \exp \left(\delta_{2} \operatorname{cont}_{i j}+\delta_{3} \text { lang }_{i j}+\delta_{4} \operatorname{ccol}_{i j}+\delta_{5} \operatorname{col}_{i j}+\delta_{6} \text { landlock }_{i j}+\delta_{7} R T A_{i j}\right)
$$

Here $d_{i j}$ represents distance between the countries, while cont $t_{i j}$, lang $g_{i j}$, ccol $l_{i j}$, colij, landlock $k_{i j}$ and RTA $A_{i j}$ are dummy variables representing whether two countries sharing a common border, common language and common colonizer, whether one of the countries was a colony of the other country, whether one of the two or both countries are landlocked country and whether there is a regional trade agreement between the countries (Bacchetta, Beverelli, Cadot, Fugazza, Grether, Helble, Nicita and Piermartini 2012).

The econometric specification of the gravity model is completed when equation 4 is inserted in equation 3 . However, there are challenges to overcome to estimate the model and obtain unbiased results. The problem with estimating equation (2) is mainly about MTRs which are not directly observable. In the gravity literature there are different ways of proxying for MTR terms. A widely used method is using importer and exporter country fixed effects to control for country specific characteristics (Rose and van Wincoop 2001; Baldwin and Taglioni 2006; Baier and Bergstrand 2007; Anderson and Yotov 2010). In this study this approach is applied. Therefore, time varying importer and exporter country dummies control for MTRs together with $\mathrm{Yi}$ and $\mathrm{Yj}$ in equation (2).

There are 3 other challenges to estimate the model especially for the effects of FTAs. First one is the presence of zero trade flows. The information contained in zero trade flows can't be taken into account if Ordinary Least Square (OLS) method, the most widely used technique to estimate the gravity models, is used. The second one is the heteroscedasticity of trade data which is known to plague data and cause biased and inconsistent estimates if OLS method is applied. The third one is the endogeneity of free trade agreements and in more general terms all trade policies. If the unobservable linkage between the trade policy and the error term is not taken into consideration, the results of the estimation could be biased. The literature proposes to apply Poisson pseudomaximum-likelihood (PPML) estimator advocated by Santos Silva and Teneyro (2006) as a solution to challenge one and two. Santos Silva and Teneyro show that PPML generates robust results even when there are many zero trade values in the data set and at the same time it is consistent in the presence of heteroskedasticity. The study of Santos Silva and Teneyro (2006) suggest that, according to Monte Carlo simulations, estimates obtained using OLS models in the presence of heteroscedasticity are severely biased while PPML method is robust to different patterns of heteroskedasticity. Regarding the endogeneity of the FTAs which is the third challenge, the literature proposes to use country-pair fixed effects (Baier and Bergstrand 2007; Dai et al. 2014; Anderson and Yotov 2016). According to Baier and Bergstrand (2007), the set of pair fixed effects which absorb all the bilateral covariates that do not change in time, eliminates the unobservable linkage between endogenous trade policy variable and the error term. When the pair fixed effects are used, because of perfect collinearity, all the time-invariant bilateral effects included in equation 4 will be dropped. If the time-invariant bilateral effects are dropped and equation 4 is inserted in equation 3 and then time varying importer and exporter country dummies are inserted to control for MTRs, the following equation is obtained:

$$
X_{i j, t}=\exp \left(\eta_{i, t}+\psi_{j, t}+\gamma_{i j}+\alpha S T A W_{i j, t}+\beta S T A T_{i j, t}\right)+\varepsilon_{i j, t}
$$

This model which is used in this study is in line with the recent advances in the literature. Here $X_{i j}, t$ represents the trade flows from country i towards country $j$ at time $t, \eta_{i t}$ and $\psi_{j \mathrm{jt}}$ represent the exporter and importer time varying fixed effects which account for MTRs in structural gravity equation, pij represents the pair fixed effects introduced to control the endogeneity.

EIAs are one of the most important determinant of international trade flows. Therefore, the presence of a bilateral or multilateral EIA between the countries included in the data set is taken into consideration in the model and represented with a dummy named STAW. STAW dummy changes according to the estimate. It is always all the EIAs between the partners excluding the FTA/FTAs that we want to measure the effect of. It takes the value of 1 if a country pair has an EIA in force in the related year and 0 if there is no EIA in that year. Finally, STAT is the dummy variable indicating the presence of FTA between Turkey and the related country. STAT dummy changes according to the estimation. The estimation approach is based on to recover the macro effects, individual FTA effects and trade direction specific effects. In this context, it is started by estimating the average overall effect of all FTAs and the FTAs in force concluded by Turkey. Then, it is continued with decomposing this average overall effect into agreement specific effects for each agreement. For this purpose, earlier analysis is modified to include a separate dummy for each agreement. Then, it is continued with decomposing the effects one step further into direction specific effects within the agreement. In addition to STAW and STAT, there are many other dummies generated for importer time/exporter time/pair fixed effects. For the panel data set with 90 countries trading with each other over 29 years, there are $5220(90 \times 2 \times 29)$ time varying importer/exporter fixed effects 
and 8010 (90x89) time invariant pair fixed effects. In this situation, a long computing time is required for estimation in STATA. For that reason, ppml_panel_sg command of Zylkin (2017) is used for computations in STATA which enables faster computation of many fixed effects. Ppml_panel_sg is an estimation command for PPML regression for panel gravity models with time varying importer and exporter fixed effects and time invariant pair fixed effects. It is strictly intended for settings where the dependent variable is spatial flows from one location to another such as international trade flows or migration flows.

\subsection{Data}

The dataset in this study is a panel arranged by country pair and year. It includes the aggregate bilateral trade flows of goods among pairs of 90 countries during the period 1988-2016. Normally there are 92 countries included in the dataset but due to discontinuity of the trade data Belgium - Luxembourg and Serbia - Montenegro are considered as a single country. In the dataset, each country pair is represented twice depending on the direction of the trade; once as ij and once as ji. When 1988-2016 period is considered, the total trade covered by the dataset represents $92,4 \%$ of the total world trade and $96 \%$ of Turkey's international trade.

Data on trade flows come from World Trade Flows (WTF) Bilateral Trade Database developed by Feenstra and Romalis and UN COMTRADE Database where needed. The data on EIAs around the world, which is needed for STAW dummy, is from "Database on Economic Integration Agreements" constructed by Jeffrey Bergstrand. This dataset is updated by the authors using data on some additional years (2013-2016) from the WTO Regional Trade Agreements Information System (RTA-IS). In the formation of this dummy variable; free trade agreements, customs unions, common markets and economic unions are considered as the presence of EIA. Data on Turkey's FTAs, which is needed for STAT dummy, come from the Ministry of Trade in Turkey.

\section{FINDINGS AND DISCUSSIONS}

In this section the results of the gravity estimations are explained. Estimations are generated using equation (5) in 6 different sets.

(1) First, the average ex-post effect of Turkey's all FTAs (except the ones entered into force in 2016 and later) on trade between Turkey and the partner of the agreement is estimated. This is a symmetric approach where the average effect on total bilateral trade is estimated. In other words, the impact on Turkey's total export to the partners and total imports to Turkey from partners are assumed to be symmetric. The results are listed in Table 1.

Table 1: Average ex-post effect of Turkey's all FTAs

\begin{tabular}{llll}
\hline Agreement & Coefficient $(\boldsymbol{\beta})$ & s.e. & Change (\%) \\
\hline All FTAs & $0.192^{* *}$ & 0.056 & 21.17 \\
Exportation from Turkey & $0.164^{*}$ & 0.072 & 17.82 \\
Importation to Turkey & $0.217^{* *}$ & 0.077 & 24.23 \\
\hline ** and * show the significance level at 1\% and 5\% respectively &
\end{tabular}

In Table 1, first column shows the agreement/direction of the trade within the agreement, second column shows the estimated $\beta$ value which is the coefficient of STAT dummy variable, third column shows the standard errors and the fourth column shows the corresponding \% change in trade. The results of this estimation indicate that FTAs concluded by Turkey had a trade promoting effect in general. On average, Turkey's FTAs increased trade flows between Turkey and the respective countries by $21.17 \%$ ( $\mathrm{e}^{0.192}$ 1).

(2) Considering the possibility that the trade affects may vary regarding the direction of trade, direction specific effects (exportation from Turkey to FTA partners and importation to Turkey from FTA partners) are estimated. This is an asymmetric approach which allows measuring the impact on Turkey's import from partner countries and Turkey's export to the partner countries separately. The result listed in Table 1 suggest that, FTAs had a positive effect on both exports and imports of Turkey. The effect on imports is more than the effects on exports. Indeed, importation to Turkey from the FTA partners increased by $24.23 \%$ while the exportation of Turkey to these countries increased by $17.82 \%$ due to the FTAs.

(3) As some of the FTAs included in the previous estimations are no longer in force, the same estimations are repeated this time only for the FTAs that are in force (as of 2016). This is again a symmetrical approach. Results are listed in Table 2. 
Table 2: Average ex-post effect of Turkey's FTAs that are in force

\begin{tabular}{llll}
\hline Agreement & Coefficient $(\beta)$ & s.e. & Change (\%) \\
\hline FTAs in Force & $0.243^{* *}$ & 0.066 & 27.51 \\
Exportation from Turkey & $0.226^{*}$ & 0.104 & 25.36 \\
Importation to Turkey & $0.258^{* *}$ & 0.080 & 29.43 \\
\hline ***
\end{tabular}

$* *$ and ${ }^{*}$ show the significance level at $1 \%$ and $5 \%$ respectively

The results show that, when only the FTAs in force are taken into consideration, they again had trade promoting effect and this time the trade promoting effect of FTAs is slightly higher. On average, Turkey's FTAs currently in force had a partial average effect equal to $27.51 \%$ increase on trade.

(4) Similar to second estimation, the effects of FTAs in force are examined with an asymmetric approach for two different directions of trade: Exports from Turkey and imports to Turkey. The results of direction specific estimate about the FTAs in force listed in Table 2 shows that, though the FTAs increased both exports and imports of Turkey, as in the previous case the increase in imports of Turkey is higher than the increase in exports of Turkey. When the results are evaluated as \% increase, importation to Turkey from the FTA partners increased by $29.43 \%$ while the export of Turkey to these countries increased by $25.36 \%$ due to the FTAs.

(5) To analyse the potential heterogeneity in individual FTA effects, the previous specification is extended and FTA effects are allowed to vary at the level of agreement similar to the approach taken in the studies of Kohl (2014) and Baier, Yotov and Zylkin (2016). This is also a symmetric approach. In this estimation, only the effects of FTAs in force (as of 2016) are included as the others are no longer in force. Therefore 16 separate estimates are made for each agreement. In addition to these agreement specific estimates, the effect of EFTA agreement is estimated separately for EFTA members, i.e. Norway, Switzerland and Iceland. Therefore, in total 19 estimates are made. The results are summarized in Table 3.

Table 3: Agreement specific effects

Positive Effects

\begin{tabular}{llll}
\hline Agreement & Coefficient $(\boldsymbol{\beta})$ & s.e. & Change (\%) \\
\hline Israel & $0.837^{* *}$ & 0.228 & 130.94 \\
Bosnia and Herzegovina & $0.666^{* *}$ & 0.126 & 94.64 \\
Morocco & $0.600^{* *}$ & 0.095 & 82.21 \\
Malaysia & $0.433^{* *}$ & 0.076 & 54.19 \\
Egypt & $0.326^{* *}$ & 0.077 & 38.54 \\
South Korea & $0.313^{* *}$ & 0.057 & 36.75 \\
Mauritius & $0.295^{* *}$ & 0.102 & 34.31 \\
Serbia and Montenegro & $0.177^{* *}$ & 0.062 & 19.36 \\
\hline Negative Effects & & & \\
Albania & $-0.280^{*}$ & 0.138 & -32.31 \\
Palestine & $-0.189^{*}$ & 0.094 & -20.80 \\
\hline Insignificant Effects & & & \\
\hline EFTA & 0.152 & 0.082 & - \\
Norway & 0.335 & 0.210 & - \\
Switzerland & 0.117 & 0.078 & - \\
Iceland & 0.732 & 0.440 & - \\
Chile & -0.273 & 0.142 & - \\
Macedonia & -0.135 & 0.152 & - \\
Tunisia & 0.040 & 0.109 & - \\
Georgia & -0.241 & 0.304 & - \\
Jordan & -0.018 & 0.111 & - \\
\hline ** and * show the significance & &
\end{tabular}

${ }^{* *}$ and ${ }^{*}$ show the significance level at $1 \%$ and $5 \%$ respectively 
The results show that, similar to the findings of Kohl (2014) and Baier Yotov and Zylkin (2016), the effects of Turkey's FTAs differ very much both quantitatively and qualitatively. Out of 16 agreements, 8 (50\%) of them had a statistically significant effect on promoting trade while 2 (\%12.5) of them had a statistically significant negative effect and $6(37.5 \%)$ of them had statistically insignificant effect on trade between Turkey and her partners. The agreements with Israel, Bosnia and Herzegovina, Morocco and Malaysia had a strong positive effect on trade. Agreements with Egypt, South Korea, Mauritius and Serbia and Montenegro had also positive effect on trade. However, the effect is modest when compared to the others. The \% change in the trade for each agreement is given in Table 3. Interestingly not all the FTAs had a positive and statistically significant effect on trade. It is found that there is no statistically significant FTA related effect on bilateral trade due to the FTAs between Turkey and EFTA, Chile, Macedonia, Tunisia, Georgia and Jordan. Even more interestingly, agreements with Albania and Palestine turned out to be negatively affecting the trade between Turkey and these countries. This finding is contrary to common expectation that FTAs increase the trade. The substantial difference in the results both in qualitative and quantitative means proves that; finding for one particular agreement cannot be generalized for other agreements and FTAs not necessarily promote trade between the partners.

(6) In order to analyse the within agreement heterogeneity, the individual FTA effects are allowed to vary asymmetrically at the level of direction of trade. In other words, exports from Turkey and imports to Turkey are examined separately similar to the approach taken in the study of Baier Yotov and Zylkin (2016). For 19 agreements, 38 directional estimates (one for Turkey's exports and one for Turkey's imports) are made in total. The results are shown in Table 4.

Table 4: Direction specific effects within the agreement

\begin{tabular}{|c|c|c|c|}
\hline Direction of Trade & Coefficient ( $\beta$ ) & s.e. & Change (\%) \\
\hline Turkey $\rightarrow$ Israel & $1.094 * *$ & 0.151 & 198.62 \\
\hline Israel $\rightarrow$ Turkey & $0.500 * *$ & 0.121 & 64.87 \\
\hline Turkey $\rightarrow$ Bosnia Herzegovina & $0.673^{* *}$ & 0.145 & 96.01 \\
\hline Bosnia Herzegovina $\rightarrow$ Turkey & $0.631 * *$ & 0.156 & 87.95 \\
\hline Turkey $\rightarrow$ Morocco & $0.646 * *$ & 0.106 & 90.79 \\
\hline Morocco $\rightarrow$ Turkey & $0.515^{* *}$ & 0.141 & 67.36 \\
\hline Turkey $\rightarrow$ Malaysia & $0.163^{* *}$ & 0.063 & 17.70 \\
\hline Malaysia $\rightarrow$ Turkey & $0.484^{* *}$ & 0.056 & 62.25 \\
\hline Turkey $\rightarrow$ Egypt & $0.355^{* *}$ & 0.098 & 42.62 \\
\hline Egypt $\rightarrow$ Turkey & $0.267 * *$ & 0.086 & 30.60 \\
\hline Turkey $\rightarrow$ South Korea & 0.048 & 0.050 & - \\
\hline South Korea $\rightarrow$ Turkey & $0.343^{* *}$ & 0.048 & 40.92 \\
\hline Turkey $\rightarrow$ Mauritius & $0.364 * *$ & 0.067 & 43.91 \\
\hline Mauritius $\rightarrow$ Turkey & -0.048 & 0.178 & - \\
\hline Turkey $\rightarrow$ Serbia-Montenegro & $0.146^{*}$ & 0.061 & 15.72 \\
\hline Serbia-Montenegro $\rightarrow$ Turkey & $0.293 * *$ & 0.077 & 34.04 \\
\hline Turkey $\rightarrow$ Albania & $-0.358 * *$ & 0.114 & -43.05 \\
\hline Albania $\rightarrow$ Turkey & $0.377^{*}$ & 0.152 & 45.79 \\
\hline Turkey $\rightarrow$ Palestine & $-0.192 *$ & 0.095 & -21.17 \\
\hline Palestine $\rightarrow$ Turkey & $0.214^{*}$ & 0.085 & 23.86 \\
\hline Turkey $\rightarrow$ EFTA & 0.211 & 0.165 & - \\
\hline EFTA $\rightarrow$ Turkey & 0.121 & 0.094 & - \\
\hline Turkey $\rightarrow$ Switzerland & 0.097 & 0.125 & - \\
\hline Switzerland $\rightarrow$ Turkey & 0.127 & 0.096 & - \\
\hline Turkey $\rightarrow$ Norway & $0.649 * *$ & 0.099 & 91.36 \\
\hline Norway $\rightarrow$ Turkey & 0.075 & 0.092 & - \\
\hline Turkey $\rightarrow$ Iceland & $1.301 * *$ & 0.119 & 267.29 \\
\hline Iceland $\rightarrow$ Turkey & 0.044 & 0.242 & - \\
\hline Turkey $\rightarrow$ Chile & $-0.501 * *$ & 0.103 & -64.04 \\
\hline Chile $\rightarrow$ Turkey & -0.120 & 0.070 & - \\
\hline Turkey $\rightarrow$ Tunisia & 0.119 & 0.094 & - \\
\hline Tunisia $\rightarrow$ Turkey & $-0.180 *$ & 0.080 & -19.72 \\
\hline Turkey $\rightarrow$ Georgia & 0.110 & 0.098 & - \\
\hline
\end{tabular}




\begin{tabular}{llll} 
Georgia $\rightarrow$ Turkey & $-1.131^{* *}$ & 0.107 & -209.87 \\
Turkey $\rightarrow$ Macedonia & -0.067 & 0.159 & - \\
Macedonia $\rightarrow$ Turkey & -0.364 & 0.209 & - \\
Turkey $\rightarrow$ Jordan & -0.084 & 0.084 & - \\
Jordan $\rightarrow$ Turkey & $0.439 * *$ & 0.146 & 55.12 \\
\hline$* *$ and $*$ show the significance level at 1\% and 5\% respectively &
\end{tabular}

One of the notable aspects of the results of this estimate is that; there is a considerable asymmetry in the effects of agreements depending on whether Turkey is the exporter or importer. Even for the agreements with statistically significant positive impacts, not all the parties are assured of benefits. On the basis of agreements, the results suggest that both exports from Turkey and imports to Turkey increased as a result of FTAs with Israel, Bosnia and Herzegovina, Morocco, Malaysia, Egypt, Serbia and Montenegro. Regarding the agreements with Israel, Bosnia and Herzegovina, Morocco and Egypt exports of Turkey increased more than the imports of Turkey. The situation is reverse for Malaysia and Serbia and Montenegro. That is, imports of Turkey from these countries increased more than the exports of Turkey to these countries. The FTAs with South Korea and Jordan had a statistically significant effect on Turkey's importation from these countries. However, there is no statistically significant FTA related impact on Turkey's exportation to these countries. In contrast, FTAs with Mauritius, Norway and Iceland had a statistically significant effect on exportation of Turkey to these countries but had no statistically significant FTA related impact on Turkey's importation from these countries. The FTAs with Albania and Palestine had a statistically significant positive effect on importation of Turkey from these countries but had a statistically significant negative effect on Turkey's exportation to these countries. Similarly, the FTA with Chile had a statistically significant negative effect on Turkey's exportation to Chile but had no statistically significant FTA related effect on importation from Chile. The FTA with Georgia had a statistically significant negative impact on Turkey's importation from Georgia but had no statistically significant FTA related effect on the exportation of Turkey to Georgia. For the rest of the pairs, FTAs had statistically insignificant effects. Detailed information is included in Table 4.

When these results are interpreted to see the impact on Turkey's exportation and importation, it is found that; FTAs with Israel, Bosnia and Herzegovina, Morocco, Malaysia, Egypt, Mauritius, Serbia and Montenegro, Norway (EFTA) and Iceland (EFTA) had a statistically significant positive effect on Turkey's exportation. However, the FTAs with Albania, Palestine and Chile had a statistically significant negative effect on Turkey's exportation to these countries. Regarding imports, FTAs with Israel, Bosnia and Herzegovina, Morocco, Malaysia, Egypt, South Korea, Serbia and Montenegro, Albania, Palestine and Jordan had a statistically significant positive effect on Turkey's importation from these countries while FTAs with Georgia and Tunisia had a statistically significant negative effect.

\section{CONCLUSION}

In this study, a very large data set consisting of bidirectional trade data covering 29 years was used for 90 countries. Of course, the findings obtained offer results from a single country, which, of course, causes us to make some limited comments and interpretations. However, the fact that Turkey is in the category of developing countries, and has many FTAs provides the feature of being a good example. Thus, the historical dimension of the FTA agreements for Turkey constitutes a valuable sample for this type of study.

There are also individual benefits for Turkey. As discussed in the literature review, there are just a few studies about the trade effects of Turkey's FTAs. To fill this gap, this paper examines the effects of Turkey's FTAs in the light of latest developments and recent econometric techniques in the empirical trade literature. It also shed light on the agreement specific and direction specific heterogeneous trade effects. To the best of our knowledge, this is the first work that examined the ex-post effects of Turkey's all FTAs that are in force in terms of individual agreement effects and within agreement effects depending on the direction of trade.

The results indicate the econometric evidence of the impact of FTAs on Turkey's trade. Estimates at the macro level show that, FTAs increased the trade between Turkey and her FTA partners in both directions. This result is in accordance with the FTA literature in general. However, the amount of increase on trade is lower when compared to the results of two different metaanalysis, one by Cipollina and Salvatici (2010) and the other by Head and Mayer (2014). The results of these meta-analysis suggest that the average effect of FTAs is $40 \%$ and $43.3 \%$ respectively. The average effect of Turkey's FTAs is lower than these values. The reason for this could be the relatively small share of FTAs in total trade of Turkey and the selection of FTA partners on the basis of alignment with EU's commercial policy due to customs union with EU. The results of directional estimates at the macro level show that FTAs of Turkey had a greater impact on her imports than exports. This finding generally seems in accordance with the ratio of export to import in Turkey. However, in order to get utmost benefit from the FTAs, the opportunities of lower/zero tariffs achieved by the FTAs should be better accounted to increase and maximize the exports. When the macro effect is decomposed 
towards the micro level, it can be precisely said that there is substantial variation and heterogeneity in the results of agreement specific estimates and direction specific estimates within the agreement. Results show that the effectiveness of the FTAs vary significantly. This finding is quite in accordance with the recent literature about the heterogeneous effects of agreements indicating the robustness of the results of this study.

When it comes to the sources of heterogeneity, the possible reasons for the differences in the ex-post effects could be the diversity in the design and implementation of FTAs and/or some other factors related to the Turkey and her partners. Regarding the design and implementation of the agreements, the differences in the initial tariffs and level/speed of trade liberalization could be a reason for the heterogeneity. Some other reasons especially about the statistically significant negative results could be the origin requirement/rules of origin which is prerequisite for enjoying the preferences and administrative burdens associated with the application of the agreements. In addition to factors relating to the design and implementation of agreement, some characteristics of the partners such as factor endowments, their openness to trade, trade complementarity between partners and some other factors could have affected the effectiveness and success of Turkey's FTAs.

FTAs, when efficient and successful, are very important tools to improve the access to international markets and increase the exports. This is very important for Turkey and other developing countries as the international trade is one of the most important impetus for economic development. Consequently, knowing that the impact of FTAs are heterogenous and not all the FTAs affected the trade of Turkey in the same positive way, it is very important to understand the reasons behind the heterogeneity and take the necessary precautions for the future negotiations in order to improve the exports and get more gains. Based on the results of this study, further research is needed to explore and fully understand the determinants of the success and efficiency of Turkey's FTAs for future policies.

\section{REFERENCES}

Anderson, J. E. (1979). “A Theoretical Foundation for the Gravity Equation.” American Economic Review 69, $106-116$.

Anderson, J. E., and van Wincoop, E.. (2003). “Gravity with Gravitas: A Solution to the Border Puzzle.” American Economic Review, 93, $170-92$.

Anderson J. E, and Yotov, Y.V. (2010). “The Changing Incidence of Geography.” American Economic Review 100(5), 2157-2186.

Anderson, J. E. (2011). “The Gravity Model”, Annual Review of Economics, Vol. 3, pp. 133-160.

Anderson, J. E., and Yotov, Y.V. (2016). “Terms of Trade and Global Efficiency Effects of Free Trade Agreements, 1990-2002.” Journal of International Economics 99[C], 279-298.

Arısoy, B., Bayar, G. and Çalışkan, Ö. (2003). “Türkiye'nin Dış Ticaret Denklemleri: Yer Çekimi, Gümrük Birliği ve Serbest Ticaret Anlaşmaları Ekonometrik Bir Yaklaşım." Middle East Technical University International Economy Congress VII.

Bacchetta, M., Beverelli, C. Cadot, O. Fugazza, M. Grether, J. M. Helble, M. Nicita, A. and Piermartini, R. (2012). A Practical Guide to Trade Policy Analysis United Nations and World Trade Organization.

Baier, S. L., and Bergstrand, J. H. (2007). “Do Free Trade Agreements Actually Increase Members' International Trade.” Journal of International Economics 71[1], 72-95.

Baier, S. L., Bergstrand, J. H. and Feng. M. (2014). "Economic Integration Agreements and the Margins of International Trade." Journal of International Economics 93, 2, 339-50.

Baier, S., J. H. Bergstrand, P. Egger, and McLaughlin, P. (2008). "Do Economic Integration Agreements Actually Work? Issues in Understanding the Causes and Consequences of the Growth of Regionalism." The World Economy 31(5), 461-497.

Baier, S.L., Bergstrand, J. H. and Clance, M. (2015). “Heterogeneous Economic Integration Agreement Effects.” CESIFO Working Paper No 5488.

Baier, S.L., Yotov, Y. V. and Zylkin, T. (2016). “On the Widely Differing Effects of Free Trade Agreements: Lessons from Twenty Years of Trade Integration." CESIFO Working Paper No 6174.

Baldwin, R., and Taglioni, D. (2006). "Gravity for Dummies and Dummies for Gravity Equations." National Bureau of Economic Research Working Paper 12516, NBER.

Bergstrand, J. H. (1985). "The Gravity Equation in International Trade, Some Microeconomic Foundations and Empirical Evidence." Review of Economics and Statistics 67: 474-81.

Bergstrand, J. H. (1989). "The Generalized Gravity Equation, Monopolistic Competition, and Empirical Evidence." Review of Economics and Statistics 71: 143-153. 
Bergstrand, J. H., Baier, S. Sunesen, E. R. and Thelle, M. H. (2011). "Ex-Post Assessment of Six EU Free Trade Agreements, An Econometric Assessment of Their Impact on Trade." Informed Decisions, Copenhagen Economics.

Bergstrand, J. H., Larch, M. and Yotov, Y.V. (2015). “Economic Integration Agreements, Border Effects, and Distance Elasticities in Gravity Equations." European Economic Review 78, 307-327.

Andrew, B. Eaton, J. Jensen, J. B. and Kortum, S. S. (2003) "Plants and Productivity in International Trade." American Economic Review 93(4), 1268-1290.

Carrere, C. (2006). "Revisiting the Effects of Regional Trade Agreements on Trade Flows with Proper Specification of the Gravity Model." European Economic Review 50, 223-247.

Cipollina, M., and Salvatici, L. (2010). “Reciprocal Trade Agreements in Gravity Models: A Meta-Analysis." Review of International Economics 18(1), 63-80.

Dai, M., Yotov, Y. V. and Zylkin, T. (2014). “On the Trade-Diversion Effects of Free Trade Agreements.” Economics Letters 122(2), 321-325.

De Benedicts, Taglioni, L. (2011). "The Gravity Model in International Trade” in De Benedicts, L., Salvatici, L. (Eds), The Trade Impact of European Union Preferential Policies: An Analysis Through Gravity Models. Springer, 55-90 (Chapter 4)

Deardorff, A. (1998). "Determinants of Bilateral Trade: Does Gravity Work in a Neoclassical World?." in The Regionalization of the World Economy, ed. by J.A. Frankel (Chicago: University of Chicago Press), 7-31.

Eaton, J. and Kortum, S. (2002). “Technology, Geography and Trade.” Econometrica 70, 1741-1779.

Egger, P. and Larch, M. (2011). “An Assessment of the Europe Agreements' Effects on Bilateral Trade, GDP, and Welfare." European Economic Review 55[2], 263-279.

Eicher, T., and Henn, C. (2011). "In Search of WTO Trade Effects: Preferential Trade Agreements Promote Trade Strongly but Unevenly." Journal of International Economics 83, 137-153.

Frede, J., Yetkiner, H.: (2017). The Regional Trade Dynamics of Turkey: A panel data gravity model, The Journal of International Trade and Economic Development https://doi.org/10.1080/09638199.2017.1279205.

Head, K., and Mayer, T. (2014). “Gravity Equations: Workhorse, Toolkit, and Cookbook.” in Gopinath, G., Helpman, E., and Rogoff, K. (eds), Handbook of International Economics Vol. 4, Oxford: Elsevier B. V.

Helpman E., and Krugman, P. (1985). Market Structure and Foreign Trade: Increasing Returns, Imperfect Competition and the International Economy Cambridge, MIT Press.

Kepaptsoglou, K., Karlaftis, M. G. and Tsamboulas, D. (2010). "The Gravity Model specification for Modelling International Trade Flows and Free Trade Agreement Effects: A 10-Year Review of Empirical Studies." The Open Economics Journal 3, 1-13.

Kohl, T. (2014). “Do We Really Know that Trade Agreements Increase Trade?” Review of World Economics 150(3), 443-169.

Kohl, T., Brakman, S. and Garretsen, H. (2016). "Do Trade Agreements Stimulate Trade Differently? Evidence From 296 Trade Agreements." World Economy 39(1), 97-131.

Krugman, P., (1980). “Scale Economies, Product Differentiation, and the Patterns of Trade." American Economic Review 70(5): 950-59.

Kütük, M. Akbostancl; E. (2016) Do Regional Trade Agreements Actually Increase Turkey's Foreign Trade, METU Studies in Development, 43, 257-288

Magee, C. (2008). “New Measures of Trade Creation and Trade Diversion.” Journal of International Economics 75(2), 349-362.

Meade, J. (1955). The Theory of Customs Unions Amsterdam: North-Holland.

Melitz M. J.(2003). “The Impact of Trade on Intra-industry Reallocations and Aggregate Industry Productivity.” Econometrica $1695-1725$.

Mölders, F., and Volz, U. (2011). "Trade Creation and the Status of FTAs: Empirical Evidence from East Asia." Review of World Economics/Weltwirtschaftliches Archiv 147(3), 429-456.

Özkaya, H. (2011). “ikili ve Çok Taraflı Anlaşmaların Türkiye’nin İhracatı Üzerine Etkisi.” Doğuş Üniversitesi Dergisi 12(2), $279-288$.

Rose, A., and van Wincoop, E. (2001). "National Money as a Barrier to International Trade: The Real Case for Currency Union." American Economic Review 91(2): 386-90.

Silva, S.J. M. C., and Tenreyro, S.. (2006). "The Log of Gravity." The Review of Economics and Statistics 88[4], 641-658.

Tinbergen J. 196). "An Analysis of World Trade Flows." Shaping the World Economy” The Twentieth Century Fund, New York: 1-117. 
Türkcan, K., and Pişkin, E. (2014). "The Effects of The Trade Agreements on The Dynamics of Turkey's Export: Extensive and Intensive Margins." MPRA Paper No 59841.

Viner, J., 1950. The Customs Union Issue. New York: Carnegie Endowment for International Peace.

Yotov, Y.V., Piermartini, R. Monteiro, J. A. and Larch, M. (2016). An Advanced Guide to Trade Policy Analysis: The Structural Gravity Model United Nations and World Trade Organization.

Zylkin, T. (2016). "Beyond Tariffs: Quantifying Heterogenity in the Effects of Free Trade Agreements" National University of Singapore Global Production Networks Centre Faculty of Arts and Social Sciences Working Paper Series, GPN 2016-006.

Zylkin, T. (2017). "PPML_PANEL_SG: Stata Module to Estimate "Structural Gravity” Models via Poisson PML." https://ideas.repec.org/c/boc/bocode/s458249.htm 